\title{
A field erodibility testing device for scour evaluation of bridges
}

\author{
M. Zinner, T. Meyer, H. Shan \& J. Shen \\ Genex Systems TFHRC, McLean, Virginia, USA
}

B. Bergendahl \& K. Kerenyi

Federal Highway Administration TFHRC, McLean, Virginia, USA

\begin{abstract}
Evaluation of scour in cohesive soil requires a good understanding of hydraulic erosion power from stream flow and the erosion resistance of the soil. In order to develop more reliable scour evaluation methods, the US Federal Highway Administration is investigating a few approaches for evaluating erosion resistance of cohesive soil. The In-situ Scour Testing Device (ISTD) produces a horizontal flow to simulate the flood conditions in an open channel and test the soil for erodibility. The erosion head assembly is compact in size and fits into the steel casing commonly used with hollow stem augers in a routine geotechnical subsurface exploration. The ISTD can be deployed to any depth that pier scour may reach to test the local material for erosion resistance. This device is calibrated using lab erosion testing devices and has been tested in the field.
\end{abstract}

\section{INTRODUCTION}

Bridge scour hazard has caused a significant number of bridge failures in the United States in past decades. It was among the top issues in bridge design and maintenance (Lee et al., 2011). As a part of the effort in implementing more rigorous scour evaluation procedures for bridge design, FHWA investigated proper approaches and supporting testing equipment that provide critical information in soil resistance to erosion power. Two parallel studies included designing an Ex situ Scour Testing Device (ESTD, Shan 2010, 2011) and an Insitu Scour Testing Device (ISTD). The ISTD developed in this study was purported to measure erodibility of soils around bridge piers. This development of ISTD is essential for the assessment of the stability of existing bridges and could potentially increase the safety of new bridges with minimal increase in cost.

In the past two decades, several in-situ devices had been developed to study the erosion of field cohesive sediments. Maa et al. (1993) developed the Virginia Institute of Marine Science (VIMS) sea carousel, a circular flume, to erode river sediment. Maa et al. (1995) and Williamson and Ockenden (1996) measured the shear stress with hot film shear stress sensors under different flow conditions. Ravens and Gschwend (1999) designed a simple rectangular duct with a cutout on the bottom to entrain the sediment underneath it. They related the shear stress to the flow rate by assuming uniform roughness throughout the duct. Houwing and van Rijn
(1998) designed an in-situ erosion flume (ISEF). Aberle et.al (2003) and Debnath et al. (2007) developed NIWA-I and NIWA-II in-situ flow-through flumes usable in water depths from 0.25 to $15 \mathrm{~m}$. In these devices, the bed shear stress was obtained by fitting the measured velocity to a log-law profile.

The aforementioned devices have collected valuable data on erosion of sediments on the surface layers of the streambed. The capability of obtaining erosion resistance information of sediments at a certain depth below the streambed is not readily available. While the surface erosion data is valuable, the information on the erodibility of material below the stream bed surface is vital to bridge foundation design, since the flood conditions cut through layers of bed material before it undermines the bridge foundation or induces other critical stability issues near bridge piers. The proposed ISTD can measure the erodibility of sediments beneath the surface of the riverbed and provide bridge engineers data for a comprehensive assessment regarding the risk of failure associated with scour.

\section{NEXT GENERATION SCOUR EVALUATION}

The current scour evaluation approach in practice uses relatively simple equations that calculate scour depth from a few parameters such as pier size, magnitude of contraction, upstream depth/velocity, and bed surface material. They do not adequately capture the variation caused by local flow conditions and 
material composition in the bridge foundation. The next-generation scour evaluation method requires proper hydraulic modeling to obtain erosion power from the flow generated by the flood and data on the erodibility of the bed material. The hydraulics erosion power from the flow decreases as scour depth increases. When it is greater than the erosion resistance of the soil at the corresponding depth, the scour proceeds deeper into the foundation material. Scour stops when the soil resistance to erosion is equal to or greater than the hydraulic erosion power. A graphical illustration of the point of equilibrium is shown in figure 1 . Note that the representation of hydraulic erosion power is currently under development. It may eventually be formulated with one or a combination of a number of flow characteristics, such as stress, pressure fluctuation, energy dissipation, etc.

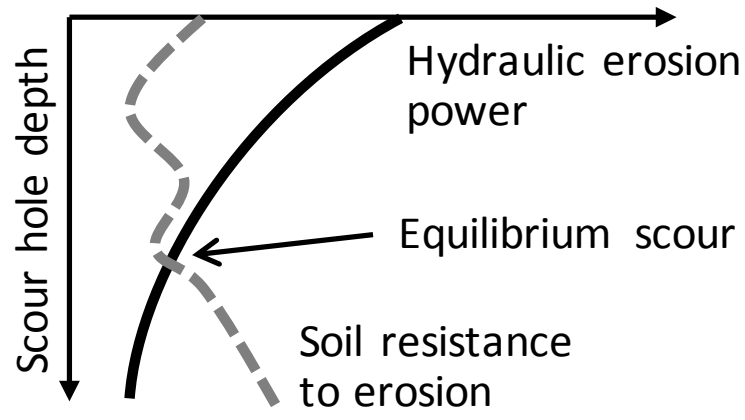

Figure 1. Determination of equilibrium scour hole.

The new scour evaluation method requires knowledge of the soil resistance to erosion at all depths that the scour may reach. Approximation of the soil resistance to erosion may be done by soil property testing through subsurface exploration, if the relationship of mechanical properties of soil to erosion resistance can be established (Shan et al., 2015). A more reliable method to obtain erosion resistance would be conducting erosion testing at various depths at the bridge site and create a soil erodibility profile.

In the long run, the erodibility properties of soil will include a complete representation of erosion rate under all conceivable shear stress levels, which will be useful in evaluating time-dependent scour in cohesive soils. For current levels of analysis, evaluating equilibrium scour only requires the identification of the critical shear stress shown in Figure 2.

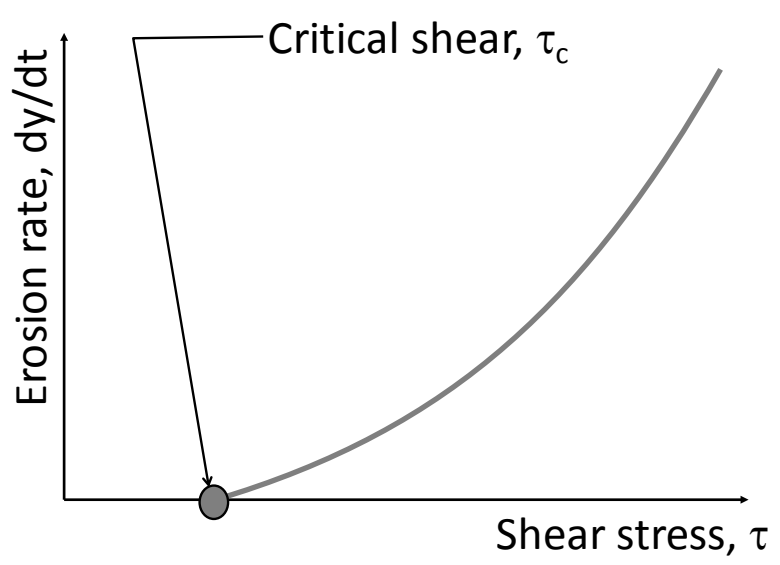

Figure 2. Critical shear stress for cohesive soils.

\section{CONCEPT AND EVOLUTION OF ISTD}

To obtain the aforementioned soil erodibility profile for design, erosion testing needs to be conducted on the stream bed surface, as well as on the sublayers extending beyond the depth where the bridge is founded (where scour may reach). In order to obtain erodibility profiles, a device that can probe into the soil layers and produce proper flow conditions for the erosion testing is necessary. The flow condition needs to reasonably simulate the near-bed layer of the open channel flow during flood occurrences in terms of its erosion potential to the stream bed. It also needs to have a good range of variability in order to accommodate any specified testing procedures that may be used to identify the soil erodibility at various depths in a short period of time. Based on these requirements, the initial concept of a controlled horizontal flow over an excavated bed surface took shape.

There are a few additional requirements to achieve the needed in-situ erosion testing conditions: (1) The tested soil needs to be physically separated by an enclosing structure from the surrounding stream bed material. (2) The device must be delivered to the depths of interest. (3) The device must provide a water supply system that offers sufficient flow rate in the erosion chamber. (4) The flow must be conditioned and oriented to offer the specific flow conditions required within the erosion chamber. (5) The waste water must be collected, treated, and stored for reuse without contaminating the stream where the testing takes place. (6) An instrumentation system that monitors the test and records critical data for the evaluation of soil erodibility and for guiding the advancement of the testing is necessary.

\subsection{U shape device}

The shape of the erosion chamber is one of the key features that directly control the testing conditions. The boundary layer near the bed produces a high 
shear stress and turbulence energy during a flood that constitutes its capability to break down the soil and transport the eroded material downstream. The pipeline and connections must eventually deliver a horizontal high speed flow in the erosion chamber. This high horizontal speed flow is necessary to accurately model the shear stresses that are experienced in the real boundary layer. A jet with an uneven velocity distribution or with an orientation perpendicular to the bed material surface is undesirable. The initial concept for the erosion chamber (Meyer et al., 2012) has a U-shaped ceiling and open bottom (Figure 3). It forces the water stream into a gradual turn at the beginning and end of the erosion chamber to reorient the vertical flow in the water supply ducts into the horizontal flow in the erosion chamber, and then to upward vertical flow in the draining ducts. It is conceivable that a curved duct would better condition the flow into the horizontal direction. However, any part of the inclusion that is not circular may impede the downward advancement of the system. One important step is to gradually deform (by erosion) the soil bed in the initial stage of the testing to conform to the shape of the ceiling in the erosion chamber (bottom of erosion head). This step was implemented in the very first round of proof-of-concept testing and set the stage for all later versions of the device.

Once the erosion chamber morphs into the preferred shape, the system maintains the shape by advancing the ceiling of the erosion chamber gradually as the soil erodes. If the chamber can be controlled to maintain the same size, the speed of the ceiling advancement would be the same as the speed of the soil erosion. This can be used as a basis for erosion rate calculation.

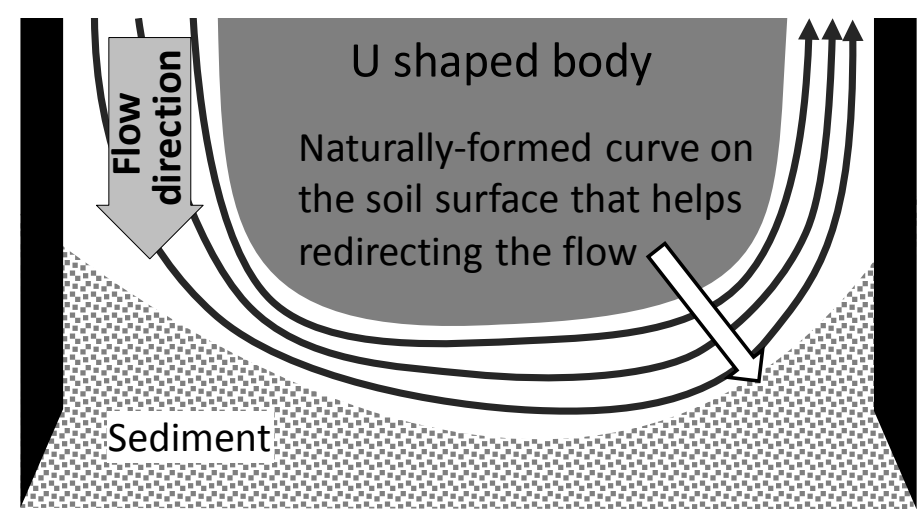

Figure 3. Horizontal flow in the erosion chamber.

\subsection{Cylindrical ISTD}

The U-shaped ISTD has a relatively compact form compared to many devices that can produce similar erosion mechanisms and is capable of advancing into a loose stream bed material more than one foot. However, at approximately 18 inch in length, it is likely too bulky for the site conditions of many bridges, and the force required to push it into the streambed is impractical because of its size and shape. A more compact, portable, and efficient design utilizing the proven concept of the U-shaped prototype is needed. With the six fundamental requirements in mind, brainstorming sessions resulted in conclusions that:

1. The erosion test should be done at the same time as the geotechnical subsurface exploration. They share similar purposes (evaluating competence of the soil) and testing requirements (e.g. boring into the ground).

2. The device should be designed as a payload deliverable by the drilling assemblies used for the subsurface exploration. All dimensions should be determined based on commonly used equipment in boring tests. The device should be standardized in order to utilize onsite equipment in conjunction with the erosion elements that can be shipped. Reliability of the erosion testing should be maximized by using well established technology to deliver the erosion elements to their testing positions.

3. Slight deviation from the linear horizontal flow over the streambed is tolerable given a sound calibration process is in place.

A new approach was initiated to accomplish these goals. In order to fit the device to a boring test rig, it needed to be in the shape and size similar to the boring samplers. The Cylindrical-ISTD (C-ISTD) was the brainchild of this concept. It was apparently challenging to put the proven concept from the Ushaped ISTD into the new form factor. Figure 4 shows the concept used in this design. The water is supplied into the erosion chamber at the perimeter and flows towards the center, then exit through a pipe. The erosion head advances as the soil erodes. The casing also advances when more soil is needed in a test.

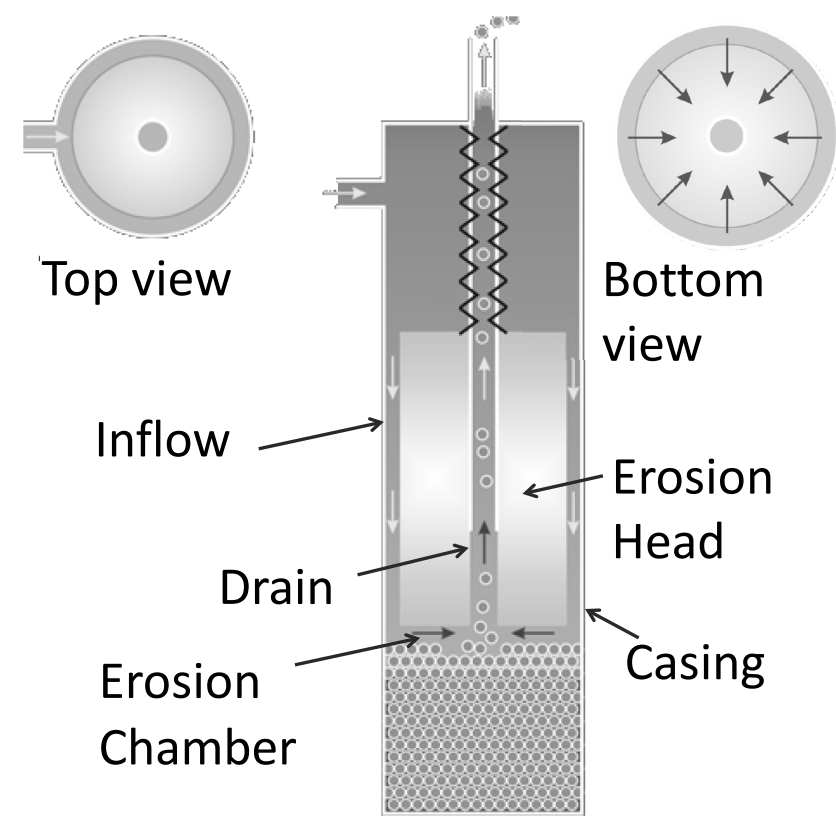

Figure 4. Cylindrical ISTD concept. 
The C-ISTD is intended to go into a hollow stem auger to a specified depth and be retrieveed after the test is completed. The most broadly used drill rigs and accessories were identified and their dimensions and specifications of the adaptors were obtained so that the device could be designed to be properly fitted to common drilling equipment. The current version of the field device has a diameter of 3.25", a length of approximately 12" (varies for different erosion head attachments), and an inner duct diameter of $1.5 "$.

\subsubsection{Enclosure for soil sample and erosion cham- ber}

To reduce clutter with the necessary pipelines, instrumentation, and wiring in the casing, a relatively large steel casing and matching hollow stem auger were chosen within the commonly used range (ID 3.5"). While geotechnical samples were typically extracted inside this sample tube, the ISTD samples stayed in place for the erosion test. The shape of sample shoes used with the steel casing was chosen and optimized to reduce the disturbance to the soil sample as the casing advances.

\subsubsection{Erosion head}

The erosion head with a circular footprint (OD 3.25") can slide inside a steel casing and perform the erosion testing. Several vertical sliders ensure a concentric position of head and tube. A centric bore through the head for the excavating water, completes this design. The upper end of this bore connects to a PVC pipe that extends above the ground. Additional shapes can be attached on the bottom, to further adjust the water current and shear distribution.

The hydraulic performance of the pipeline/erosion head assembly changes as it descends and tests deeper soil layers. The system is controlled adaptively to provide accurate flow rate and shear stress on the soil being tested. The concentric horizontal flow in the erosion chamber can be seen as a U shaped flow towards the central axis, except the cross section of the flow decreases if the height of the chamber is constant. The loose particles from the erosion are carried with the stream towards the center bore and up the PVC piping. Two coordinating pumps work together to accomplish the proper flow rate and pressure in the chamber.

If the erosion head is flat on the tip, the flow in the erosion chamber would accelerate towards the center because the flow cross section area is proportional to the radius and decreases towards the center. This would result in a significantly-varying shear stress on the soil surface. The research team conducted Computational Fluid Dynamics (CFD) modeling to optimize erosion head which produces uniformly distributed shear stress on the soil surface.. Figure 5 shows a few examples of candidate shapes for the erosion head. The currently identified best surface form for the tip of the erosion head, i.e. ceiling of the erosion chamber, is represented by the third model in Figure 5 (on the right).

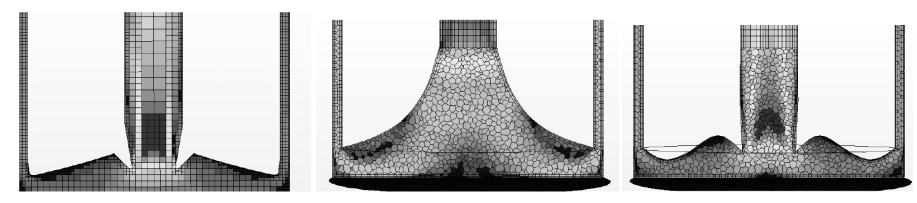

Figure 5. CFD optimization for the shape of the erosion head.

\subsubsection{Optimization of the erosion chamber}

The erosion head is designed to accomplish (1) uniform high shear stress on the soil surface, (2) neutral pressure at the corresponding depth, (3) minimal energy loss at inlet, outlet, and pipeline, and (4) proper capability for removal of the eroded material. The search for the optimal design utilizes data from CFD modeling and physical measurement of flow conditions critical to the purpose as references. In addition to the sensor introduced in the next section that provides necessary data during the erosion test, pressure taps are positioned at various sections to provide CFD validation and data for energy/pressure optimization. When hot spots for erosion are identified from CFD study and/or trial testing on soils, the shape of the erosion head is further modified to mitigate any uneven erosion.

The erosion head produces a horizontal flow in the erosion chamber. While the orientation is similar to that in a stream, the effect from the flow to the material being tested may not be identical to that in a stream because of the small footprint of the device and the radial flow condition in the erosion chamber as opposed to the straight flow condition in a stream. For obtaining the result in a limited time, the research team developed a calibration process to obtain an empirical relationship between flow rate and erosion potential (see Section 6). Analytical formulation for such relationship may be studied in the future.

\subsubsection{Water supply, drainage, and treatment}

A fresh water tank carries sufficient water to sustain the testing period of one bore hole. The flowrate of an inlet (pressure) pump and an outlet (suction) pump are controlled to produce the necessary power and to balance the pressure in the erosion chamber. This is important both for properly carrying out erosion testing and for preventing damage to the system. The waste water needs to be evacuated at a reasonably high speed to ensure that the flow has sufficient capacity to remove all possible sizes of eroded material. The effluent is treated with a "MudPuppy" that separates larger particles and filters finer particles. 


\subsubsection{Instrumentation and control system}

Operating the system requires a combination of sensors, regulating mechanisms, actuators and an active control algorithm.

The primary parameters to be controlled are the discharge, Q, shown in Figure 6 and height, d, of the erosion chamber. The main measurement is the rate of the downward movement of the soil surface, $d y / d t$. The sensors used to obtain these measurements include a displacement sensor measuring the height of the erosion chamber; a flow meter measuring the discharge, $Q$, and an encoder measuring the erosion head movement, $z$. The primary measurements can be obtained by

$e=\frac{d y}{d t}=\frac{d z}{d t}+\frac{d d}{d t}$

where e is the erosion rate, $y$ is the change of the soil surface caused by erosion, $t$ is time and $d$ is the erosion chamber height.

\section{Outlet}

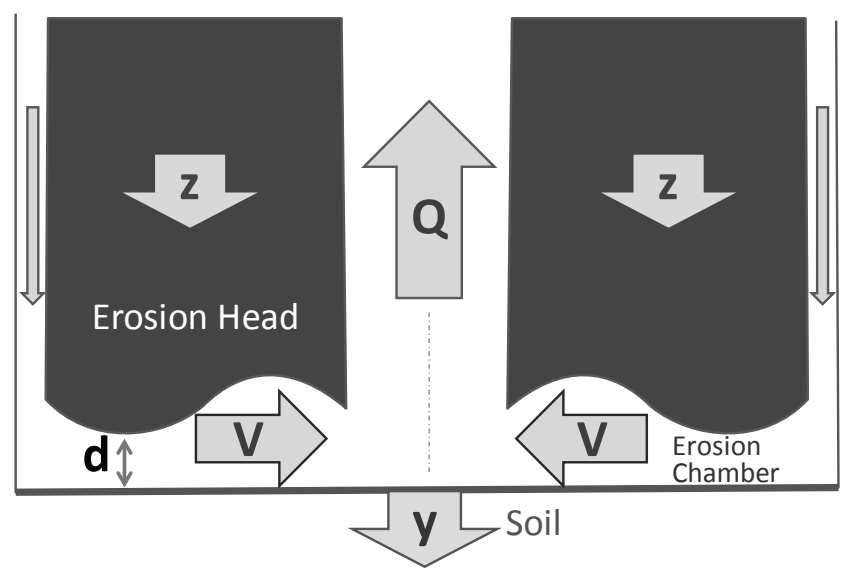

Figure 6. Control parameters.

The displacement sensor measures the height of the erosion chamber, which is a feedback for the control system that synchronizes the erosion head motion with the change of soil surface. It is placed in a very challenging environment, where velocity is high, water is turbid, and the measured surface is delicate - soft, and easily disturbed. Both mechanical sensors and non-contact sensors (ultrasonic or optical) were considered and tested. The mechanical sensor used in this device is a submersible LVDT sensor with high precision. Various shoes were fitted to the tip of the sensor to accurately position it on the surface of the soil and not disturb (increase or decrease) the erosion at the contact point. While the LVDT sensor indicates the position of the soil reliably in trial testing, it is vulnerable to fine particle deposition in field test and may become less responsive over time. Ultrasonic sensors are more resilient to turbid water than mechanical sensors and optical sensors. The greatest challenges are properly identifying moist, soft soil surface and size of the sensor.
The actuators in the control system include the inlet/outlet pumps and the motor driving the erosion head. Generally, these are controlled to maintain a constant discharge and a constant height of the erosion chamber, which provides a constant velocity and shear stress in the erosion chamber. Other programs may be developed to offer a proper balance between volume of data obtained and testing time under various site conditions.

The inlet can be configured to be open to the air or pressurized depending upon the desired testing condition. When it is open to the air, a reservoir maintains a reference water level. Control loops that sense the water level and adjust the RPM of an additional support pump are used. The pump draws from the water tank, which results in the recycling of the tested water. When the inlet is pressurized, the pump directly controls the pressure and flow rate at the entrance of the clear water into the steel casing.

Controlling the position and advancement rate of erosion head is the crucial task of this system. A specially designed linear actuator is used to accurately drive the erosion head. The control loop of the linear actuator is highly sensitive to the measurement of the height of the erosion chamber. The precision and stability of this control loop governs the accuracy of the erosion test. The linear actuator has a 5' stroke and is fixed onto a rugged aluminum frame. This frame can be positioned and leveled to the ground surface. The linear axis is powered by an electrical stepper motor. This stepper motor includes a relative encoder which allows for precise movement. The appropriate linear motion is calculated by the controlling software based on the measured gap. Figure 7 shows the result from a test run. For a constant flow rate, the erosion rate decreases when the height of erosion chamber ("gap") increases, producing a lower velocity in the erosion chamber. When the flow rate is reduced below a certain threshold, the erosion nearly stops ("Erosion rate 4" in Figure 7). This indicates that the shear stress on the soil surface is less than the critical shear stress of the material. 


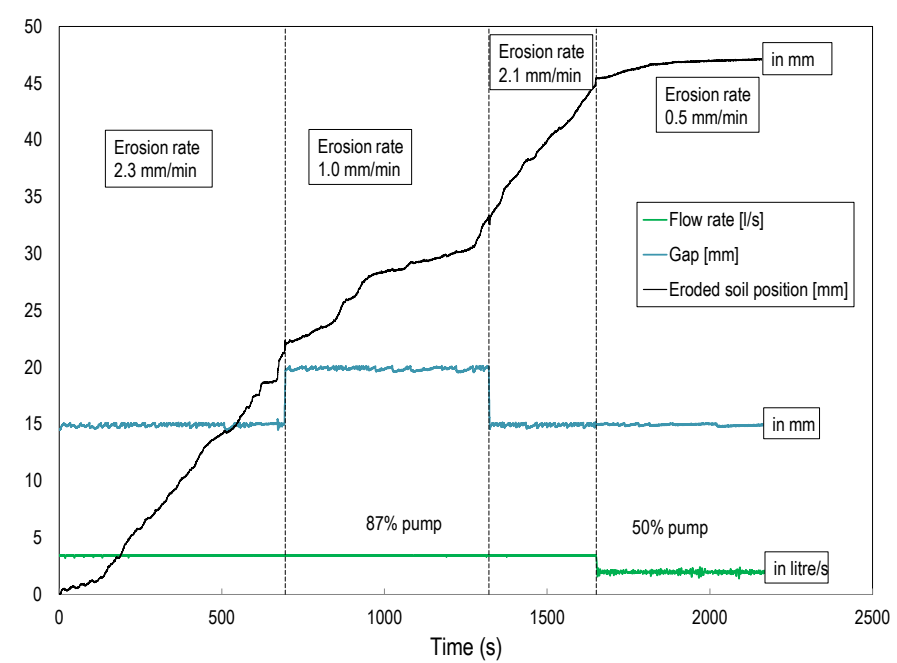

Figure 7. Variation of erosion rate with respect to flow rate and gap size.

\section{TESTING PROCEDURE}

The testing procedure varies depending upon the site conditions, required level of details, and available testing time. Figure 8 shows the general steps. For especially erosion resistant material, the erosion test may be done within small depth increments, and the erodibility profile is produced by drilling to the specified test points to conduct the erosion test. The procedure takes into consideration of granular sediments up to pebble size. If gravel layer is present with sizes greater than the removal capacity of the erosion head, the erosion head would stop advancing and the procedure would switch to an excavation mode (Step 3 in Figure 8). Geotechnical testing and sampling can be conducted during the excavation process. For more erodible material, the erosion test may be done through the entire depth range without switching to drilling. The pretest boring is conducted to assess the site conditions for the determination of a proper testing program. In routine operations, the geotechnical boring results can be used as the pretesting boring.

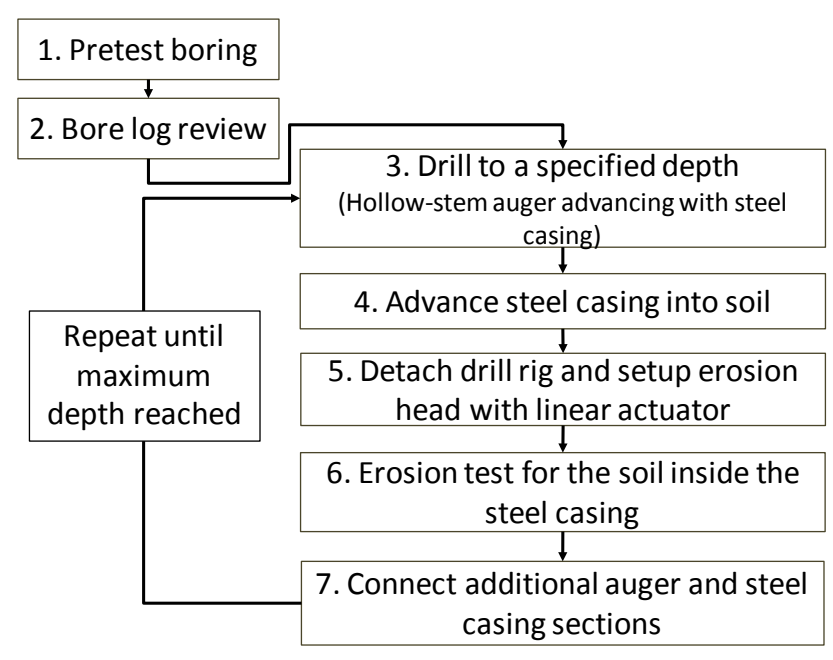

Figure 8. General testing procedure.
Test program (step 6 in Figure 8), which includes the process of varying flow rate and erosion chamber height, may have a broad range of variations, depending upon the site conditions and target soil parameters. For example, a ramped program may be used to find critical shear by recording the flow rate at the first observed movement of the soil surface. This procedure can be carried out both on dry land and in a stream (on a barge). All elements that go into the steel casing and hollow stem auger are designed to work underwater because the interior of the drilling system is flooded during the testing.

\subsection{Drilling}

The drilling equipment needs to deploy the ISTD assembly to a specified depth and provide an enclosure for the testing. There are a number of available drilling/sampling methods with corresponding assembly on the market. Considering the need of broad availability and the requirements of the erosion testing, a drill rig fitted with a continuous auger sampling assembly was selected and used with the ISTD. Using this method, a hollow stem auger drills into the soil. Inside the hollow auger, a steel casing that does not rotate with the auger is pressed into the soil below the tip of the auger. Through this advancement the steel casing fills internally with soil ready for erosion testing. Typical stroke lengths are 3 'to 5 ' depending on the local soil type. When a stroke is finished the drill rig detaches from the drilling assembly so that both the auger and steel case can be extended by attaching a new section on the top.

In general any sample system providing a continuous sample tube and minimal sample disturbance can be used for this test.

\subsection{Erosion test}

With the drill rig detached, a small reservoir (open system) or pipe fitting (pressurized system) is attached onto the steel casing. The linear actuator is firmly placed next to the drill assembly (auger and steel casing) and the erosion head is lowered inside the casing. Figure 9 shows the deployment of equipment in a field test. To reach the different test depths, 5' PVC pipe increments can be added. When the sensors on the erosion head indicate a certain distance above the test soil the pumps are started. The support pump floods the sample tube up to a maintained level. In order to initiate the test flow the suction pump is started. After a short "heat up" time the erosion head moves to close the gap to the test level.

From this point the software can be switched to an automatic control mode and will then begin maintaining the gap. A record of all the digital data is saved continuously. The erosion process goes on un- 
til a sufficient amount of data is recorded or until the sample erodes completely.

In the next step the erosion head is retracted and the test equipment demounted. To continue testing the drill rig reattaches to the tube and auger, which allows for the sampling of the subsequent soil section.

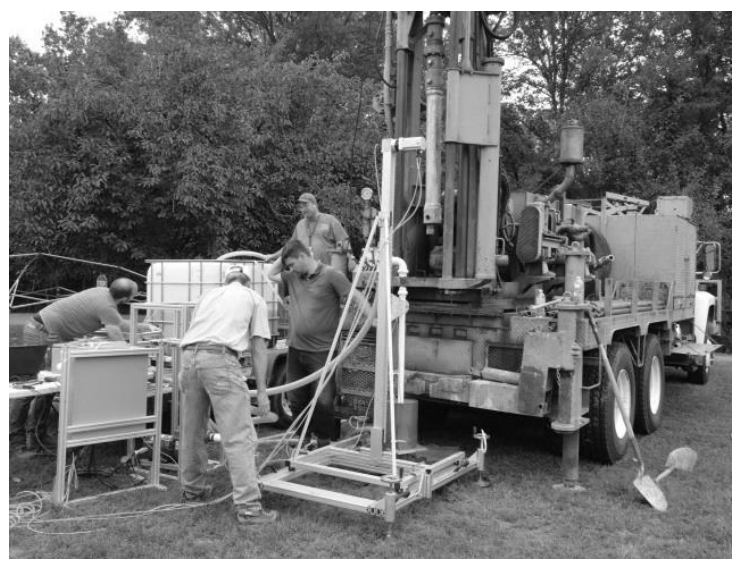

Figure 9. Deployment of equipment in a field test.

\section{FIELD TEST EXPERIENCE}

During 2015 several pilot field tests in Virginia and Maryland were performed. Although the target test areas for the ISTD are river bed soils, these tests took place on dry land for ease of access and convenient testing of questionable components. The US Geological Survey (USGS) provided critical assistance in test site selection and drilling operation. Multiple improvements to the system were recommended and implemented after each test.

The initially used LVDT sensor was proved to be insufficiently reliable when working with fine particles. These particles were deposited between the mechanical parts by the flow and occasionally impeded movement of the sensor, resulting in interruptions to the test procedure. A noncontact ultrasonic sensor scheme was subsequently implemented.

The original design assumes that the particle eroded from cohesive soil is of comparable size as the particle composition of the clay, i.e. very fine. During these field tests, it was found that some cohesive soil material broke away in larger pieces. The result was that the reading of erosion remained stationary for an extended period; then had sudden spikes. The intermittent break-off results in a stairshaped graph of erosion.

This finding indicates that there is more to learn about the erosion process and mechanics of cohesive soil that will affect future scour evaluation and final design of the ISTD. The erosion process of cohesive soil may include a combined effect of mechanical failure of fine particles, slaking, large break-offs, and failure due to defects/fissures residing in the soil body. Slaking is a time-dependent process while other mechanisms depend on stress from the flow or electromagnetic forces. The time-dependent slaking effect may be caused by high air pressure in the voids of unsaturated soil. This would likely be an important mechanism for scour on a flood plain, but is not very well documented in current scour evaluation documents.

Current ISTD testing programs do not take into consideration differences among these effects. A potentially false result of erosion may result from the slaking effect, which would not likely occur on a real stream bed that has been saturated for a long time. Once a better understanding of the erosion mechanism is reached, the testing program of ISTDs can be designed to account for each or a combination of these effects. Site selection in upcoming tests may also take this into consideration and locations within an acceptable distance to rivers may be chosen.

Since the very first iteration of design improvements, the flow rate and shear stress in the erosion chamber have been greatly increased. This enabled the ISTD to test a broader range of soils found at the test sites. To further increase the coverage, further improvement on the hydraulic system of ISTD will be done. Alternative methods to increase erosion potential will also be investigated, which may include increasing the turbulence intensity in the erosion chamber. For the same flow rate, high turbulence flow may apply more energy resulting in a higher erosion rate than that produced by less turbulent flow.

All tests up to this point are on dry land for the ease of system performance documentation and system improvement. Future test program may involve sites located in a stream.

\section{CALIBRATION}

While the test results (Figure 7) demonstrated the capability of the ISTD in obtaining the correlation between flow rate and cohesive soil erosion, a sound calibration is needed to correlate the flow rate in ISTD to that of an open channel during flood. The FHWA Hydraulics Research Program has developed an Ex-situ Scour Testing Device (ESTD) that reproduces the boundary layer of the open channel at various flow conditions. This will be done by using consistent soil samples prepared in the lab in both the ISTD and ESTD. The ESTD generates an erosion rate-to-shear relationship (Figure 10, upperleft), which is proven to be the same as the relationship in a real stream channel. The ISTD generates an erosion rate-to-flow rate relationship on the same soil (Figure 10, upper-right). It is conceivable that when the erosion rate in the two devices are the same for the same soil, there is an equivalency in the flow conditions. Therefore, by finding the bed shear in ESTD and flow rate in ISTD that produce the 
same erosion rate for the same soil sample, the ISTD results can be fully correlated to field flow conditions corresponding to the shear stress on the stream bed (Figure 10, lower).

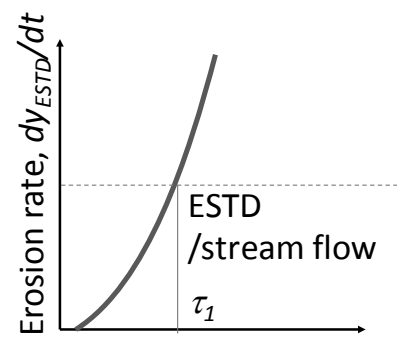

Bed shear, $\tau$
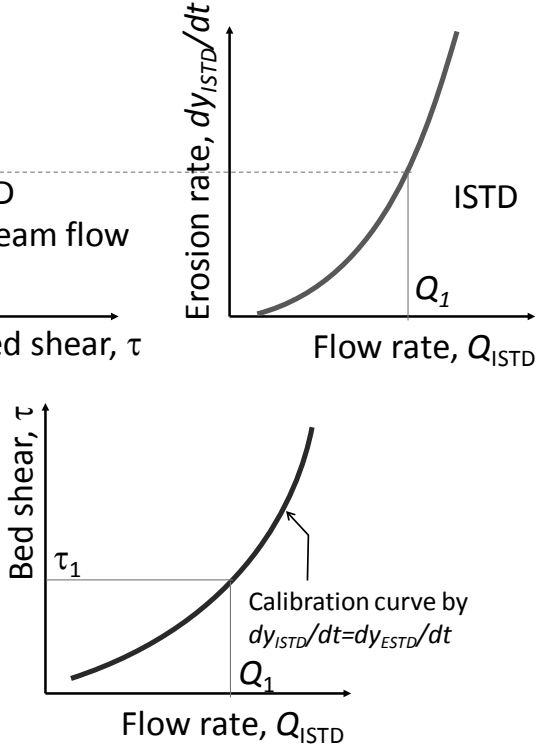

Figure 10. Calibration of ISTD with respect to stream conditions simulated by ESTD.

\section{CONCLUSION}

A field erosion testing device is being developed by the FHWA and will become an integral part of the scour evaluation for bridges in the future. Lab validation and field testing have demonstrated the effectiveness of the device and has offered information leading to possible further improvements. The compact form factor allows the device to be used during a geotechnical subsurface exploration with minimal increase in cost. Once complete and commercialized, the device will offer a soil erodibility profile at the bridge site that can produce more accurate scour evaluation and therefore reduce unnecessary conservatism in bridge construction.

\section{REFERENCE}

Aberle, J., Nikora, V., McLean, S., Doscher, C., McEwan, I., Green, M., Goring, D., \& Walsh, J. (2003). Straight benthic flow-through flume for in situ measurement of cohesive sediment dynamics. Journal of Hydraulic Engineering, 129(1), 63-67.

Debnath, K., Nikora, V., \& Elliott, A. (2007). Stream bank erosion: in situ flume tests. Journal of irrigation and drainage engineering, 133(3), 256-264.

Houwing, E. J., \& van Rijn, L. C. (1998). In situ erosion flume (ISEF): determination of bed-shear stress and erosion of a kaolinite bed. Journal of Sea Research, 39(3-4), 243-253.

Lee, G., Liang, Z., Shen, J. and O'Connor, J. (2011), Extreme Load Combinations: A Survey of State Bridge Engineers, MCEER-11-0007.

Meyer, T., Kerenyi, K., Xie, Z., Shan, H., \& Shen, J. (2012). A U-shape in-situ scour testing device. Proceedings of the ICSE-6, Paris, France, 1127-1132.
Shan, H. (2010). Experimental study on incipient motion of non-cohesive and cohesive sediments, Ph. D. dissertation, University of Nebraska-Lincoln, Nebraska.

Shan, H., Shen, J., Kilgore, R., \& Kerenyi, K. (2015). Scour in Cohesive Soils, FHWA-HRT-15-033, FHWA, Washington, DC.

Shan, H., Wagner, A., Kerenyi, K., Guo, J., \& Xie, Z. (2011). An Ex-situ Scour Testing Device for erosion research of cohesive soils. Proceedings of the engineering mechanics institute 2011 conference, Wang, M., Bernal, D., Hajjar, J. and Cao, Y. Ed., Boston, MA, 1020-1027.

Williamson HJ and Ockenden MC (1996) ISIS: An instrument for measuring erosion shear stress in situ. Estuarine, Coastal and Shelf Science, 42, 1-18 